\title{
ТРИЭТАНОЛАМИНОВЫЕ СОЛИ ВТОРИЧНЫХ АЛКИЛСУЛЬФОЭФИРОВ И ИХ ПОВЕРХНОСТНО-АКТИВНЫЕ СВОЙСТВА
}

Bce повышающиеся экологические требования к широко используемым синтетическим поверхностно-активным веществам (ПАВ) ставят перед исследователями задачу синтезировать такие ПАВ, ккоторые, обладая удовлетворительными поверхностно-активными свойствами, в то же время были бы мало токсичными и легко биоразлагаемыми, не вызывали загрязнения почвы и водоемов, имели слабое дерматологическое действие.

Ивестно, что триэтаноламиновая соль первичного лаурилсульфата является главной составной частью мнопих моющих и пеномоющих средств, например, шампуней и зубных паст $\left[^{1-7}\right]$. В Советском Союзе используется главным образом импортная триэтаноламиновая соль лаурилсульфата, которая представляет собой дефицитный продукт.

Промышленностью освоен процесс получения вторичных алкилсульфатов натрия на основе олефиновых углеводородов.

Способ получения вторичных алкильсульфатов триэтаноламина в литературе не описан, и цель настоящей работы заключалась в проверке возможности получения триэтаноламиновых солей вторичных алкилсульфоэфиров, в разработке технологии этого процесса, определении физико-химических свойств получающихся продуктов и возможности их применения.

В настоящей работе использовали фракцию олефинового сырья, получаемую путем крекинга твердых парафинов и идущую на производство пенообразователя ПО-ЗА. Фракция содержала $82 \% \alpha$-олефинов нормального строения, причем из них $39 \%$ составляли олефины $\mathrm{C}_{9}-\mathrm{C}_{10}$ и $43 \%$ - олефины $\mathrm{C}_{11}-\mathrm{C}_{13}$.

Сульфатирование проводили моногидратом серной кислоты, который добавляли постепенно при интенсивном перемешивании и охлаждении, при этом следили, чтобы температура не превышала $20^{\circ} \mathrm{C}$. Затем сульфоэфиры нейтрализовали $50 \%$-ным водным раствором триэтаноламина до $\mathrm{pH} 7,5-8$.

После добавления изопропилового спирта проходило расслоение реакционной массы на два слоя. Верхний представлял собой несульфатированные соединения и удалялся. Нижний слой использовали для экстракции растворенных несульфатированных соединений и выпаривания изопропилового спирта и части воды. 


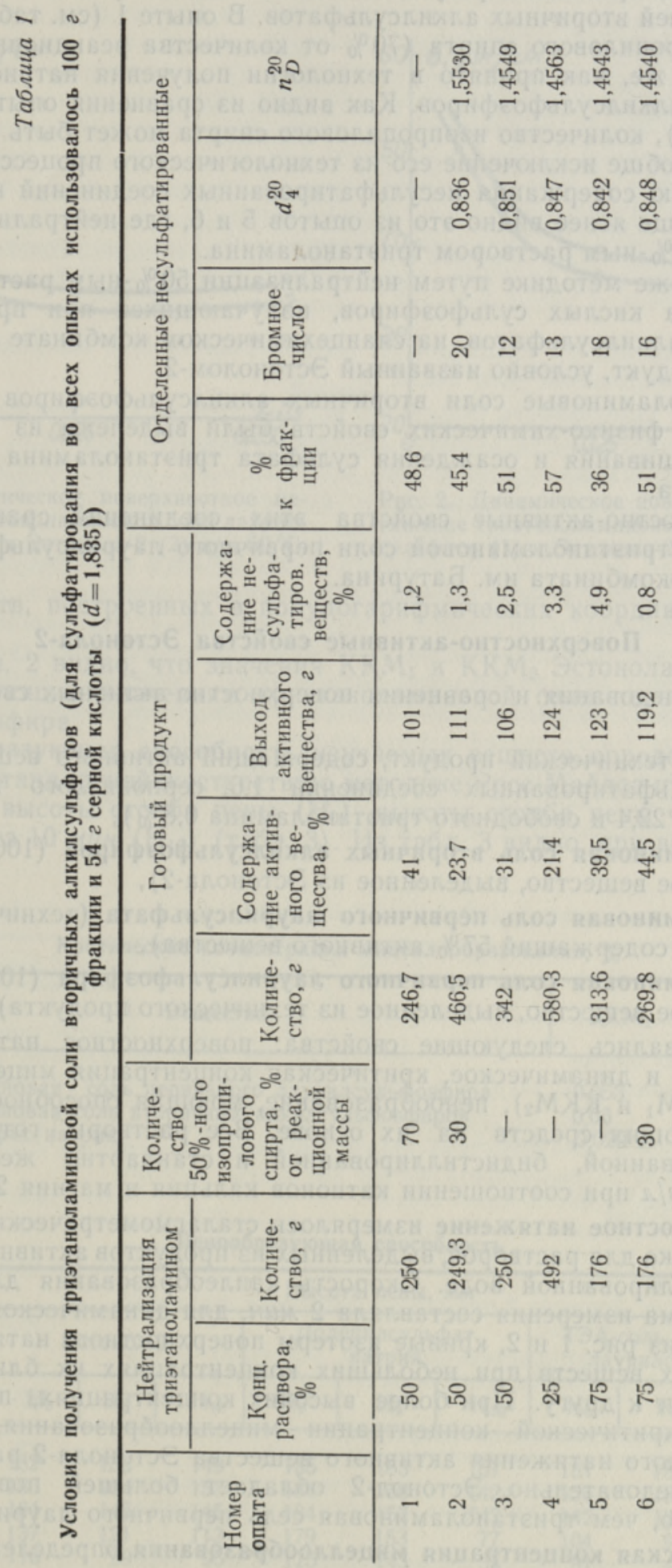


В табл. 1 приведены результаты опытов по получению триэтаноламиновых солей вторичных алкилсульфатов. В опыте 1 (см. табл. 1) количество изопропилового спирта (70\% от количества реакционной массы) было такое же, как принято в технологии получения натриевых солей вторичных алкилсульфоэфиров. Как видно из сравнения опытов 1, 2 и 3 (см. табл. 1), количество изопропилового спирта может быть уменьшено вдвое, но вообще исключение его из технологического процесса приводит к повышению содержания несульфатированных соединений в конечном продукте. Еще яснее видно это из опытов 5 и 6, где нейтрализация проводилась $75 \%$-ным раствором триэтаноламина.

По этой же методике путем нейтрализации 50\%-ным раствором триэтаноламина кислых сульфоэфиров, получающихся при производстве вторичных алкилсульфатов, на сланцехимическом комбинате «Кивиыли» получен продукт, условно названный Эстонолом-2.

Триэтаноламиновые соли вторичных алкилсульфоэфиров для определения их физико-химических свойств были выделены из Әстонола-2 путем высушивания и осаждения сульфата триэтаноламина из безводного ацетона.

Поверхностно-активные свойства этих соединений сравнивали со свойствами триэтаноламиновой соли первичного лаурилсульфата производства химкомбината им. Батурина.

\section{Поверхностно-активные свойства Эстонола-2}

Для исследования и сравнения поверхностно-активных свойств были взяты:

Эстонол-2 (технический продукт, содержащий активного вещества 49,5, несульфатированных соединений 1,6 , сернокислого триэтаноламина 22,4 и свободного триэтаноламина 0,8\%),

триэтаноламиновая соль вторичных алкилсульфоэфиров (100\%-ное активное вещество, выделенное из Эстонола-2),

триэтаноламиновая соль первичного лаурилсульфата (технический продукт, содержащий $57 \%$ активного вещества),

триэтаноламиновая соль первичного лаурилсульфоэфира (100\%-ное активное вещество, выделенное из технического продукта).

Исследовались следующие свойства: поверхностное натяжение статическое и динамическое, критическая концентрация мицеллообразования $\left(\mathrm{KKM}_{1}\right.$ и $\left.\mathrm{KKM}_{2}\right)$, пенообразование, моющая способность продуктов и моющих средств на их основе. Все растворы готовились на дистиллированной, бидистиллированной и стандартно жесткой воде (5,35 ме-экв/л при соотношении катионов кальция и магния $2: 1)$.

Поверхностное натяжение измерялось сталагмометрическим методом при $50^{\circ}$ только для растворов, выделенных из продуктов активных веществ в бидистиллированной воде. Скорость каплеобразования для статического режима измерения составляла 2 мин, для динамического -2 сек. Как видно из рис. 1 и 2, кривые изотерм поверхностного натяжения для исследуемых веществ при небольших концентрациях их близко расположены друг к другу. При более высоких концентрациях, приближающихся к критической концентрации мицеллообразования, изотерма поверхностного натяжения активного вещества Эстонола-2 расположена ниже, и следовательно, Эстонол-2 обладает большей поверхностной активностью, чем триэтаноламиновая сель первичного лаурилсульфата.

Критическая концентрация мицеллообразования определена по излому соответствующих изотерм поверхностного натяжения для исследуе- 


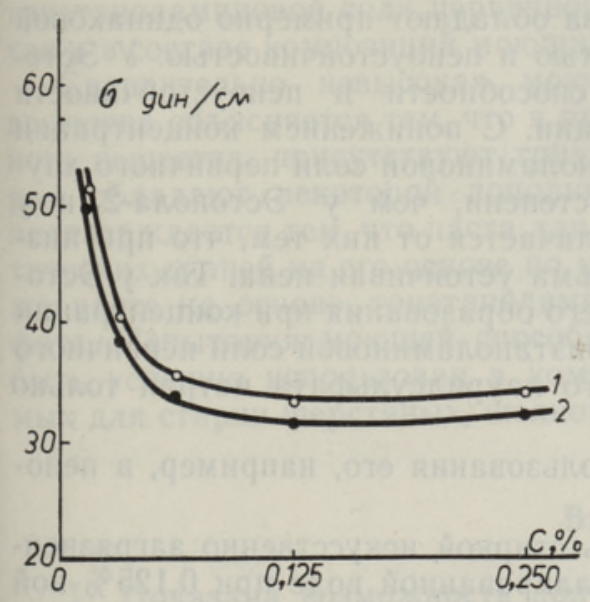

Рис. 1. Статическое поверхностное натяжение триэтаноламиновой соли лаурилсульфата (1) и Эстонола-2 (2) при $50^{\circ} \mathrm{C}$.

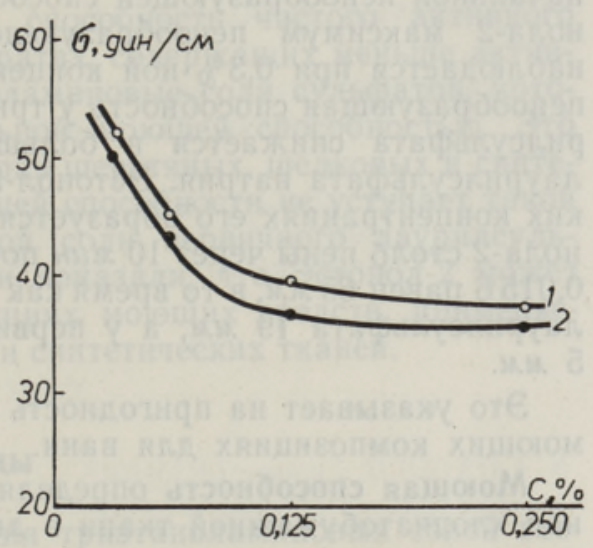

Рис. 2. Динамическое поверхностное натяжение триэтаноламиновой соли лаурилсульфата (1) и Эстонола-2 (2) при $50{ }^{\circ} \mathrm{C}$.

мых веществ, построенных в полулогарифмичеоких координатах (табл. 2).

Из табл. 2 видно, что значения $\mathrm{KKM}_{1}$ и $\mathrm{KKM}_{2}$ Эстонола-2 близки к соответствующим значениям триэтаноламиновой соли первичного лаурилсульфоэфира.

Пенообразующая способность изучаемых веществ определялась при $50^{\circ}$ в воде стандартной жесткости по методике Росс-Майлса путем замера начальной высоты столба пены $\left(\mathrm{H}_{0}\right)$, высоты столба пены через 5 мин $\left(\mathrm{H}_{5}\right)$ и через 10 мин $\left(\mathrm{H}_{10}\right)$ (табл. 3). Из табл. 3 видно, при высоких кон-

Таблица 2

Критические концентрации мицеллообразования, \%

\begin{tabular}{l|ll}
\hline \multicolumn{1}{c|}{ Вещество } & $\mathrm{KKM}_{1}$ & $\mathrm{KKM}_{2}$ \\
\hline & & \\
\hline Tриэтаноламиновая соль первичного лаурилсульфоэфира & 0,053 & 0,160 \\
Триэтаноламиновая соль вторичных алкилсульфоэфиров & 0,05 & 0,130 \\
Додецилсульфат натрия & 0,020 & 0,210
\end{tabular}

таблица 3

Пенообразующая способность

\begin{tabular}{|c|c|c|c|c|c|c|c|c|c|}
\hline \multirow{3}{*}{$\begin{array}{l}\text { Концентра- } \\
\text { ция, вес. \% }\end{array}$} & \multicolumn{9}{|c|}{ Высота пены, мм } \\
\hline & \multicolumn{3}{|c|}{ Эстонол-2 } & \multicolumn{3}{|c|}{$\begin{array}{c}\text { Додецилсульфат } \\
\text { натрия }\end{array}$} & \multicolumn{3}{|c|}{$\begin{array}{c}\text { ТЭА-соль первичного } \\
\text { лаурилсульфата }\end{array}$} \\
\hline & $\mathrm{H}_{0}$ & $\mathrm{H}_{5}$ & $\mathrm{H}_{10}$ & $\mathrm{H}_{0}$ & $\mathrm{H}_{5}$ & $\mathrm{H}_{10}$ & $\mathrm{H}_{0}$ & $\mathrm{H}_{5}$ & $\mathrm{H}_{10}$ \\
\hline 0,5000 & 182 & 156 & 149 & 185 & 163 & 157 & 181 & 156 & 153 \\
\hline 0,3000 & 185 & 164 & 153 & 184 & 158 & 142 & 156 & 130 & 124 \\
\hline 0,1250 & 164 & 145 & 145 & 184 & 157 & 142 & 142 & 125 & 120 \\
\hline 0,0625 & 137 & 121 & 113 & 179 & 153 & 77 & 104 & 97 & 52 \\
\hline 0.0312 & 116 & 99 & 95 & 175 & 143 & 35 & 81 & 44 & 31 \\
\hline 0,0156 & 84 & 69 & 65 & 142 & 85 & 5 & 65 & 25 & 19 \\
\hline
\end{tabular}


центрациях все исследованные вещества обладают примерно одинаковой начальной пенообразующей способностью и пеноустойчивостью. У Эстонола-2 максимум пенообразующей способности и пеноустойчивости наблюдается при 0,3\%-ной концентрации. С понижением концентрации пенообразующая способность у триэтаноламиновой соли первичното лаурилсульфата онижается в большей степени, чем у Эстонола-2 и у лаурилсульфата натрия. Әстонол-2 отличается от них тем, что при низких концентрациях его образуется весьма устойчивая пена. Так у Эстонола-2 столб пены через 10 мин после его образования при концентрации 0,0156 равен 65 мм, в то время как у триэтаноламиновой соли первичного лаурилсульфата 19 мм, а у первичного лаурилсульфата натрия только 5 MM.

Это указывает на пригодность использования его, например, в пеномоющих композициях для ванн.

Моющая способность определялась стиркой искусственно загрязненной хлопчатобумажной ткани в дистиллированной воде при $0,125 \%$-ной концентрации активного вещества и при 20 и $50^{\circ}$ на лабораторном лаундерометре. Расчеты произведены с иопользованием формулы КубелкиМунка.

На основе исследуемых веществ и эталонного лаурилсульфата натрня приготовлены пробы композиций моющих средств для стирки шерстяных, шелковых и синтетических тканей по стандартной рецептуре пастообразных средств, содержащих $35 \%$ активного вещества, $5 \%$ моноалкиламидов и $10 \%$ триполифосфата натрия и жидких моющих средств, которые в свою очередь содержали заменяемого активного вещества 17 , неионогенных 7 и триполифосфата калия и натрия $7 \%$.

Как видно из табл. 4 , Эстонол-2 не уступает по моющей способности

Таблица 4

Моющая способность Эстонола-2 и моющих средств на его основе, \%

\begin{tabular}{l|l|l}
\hline Исследуемое средство & При $20^{\circ} \mathrm{C}$ & При $50^{\circ} \mathrm{C}$ \\
\hline
\end{tabular}

Лаурилсульфат натрия

Триэтаноламиновая соль лаурилсульфата

Эстонол-2

Триэтаноламиновая соль вторичных алкильсульфоэфиров

Паста на основе лаурилсульфата натрия для стирки шерстяных, шелковых и синтетических тканей

Паста на основе триэтаноламиновой соли первичного лаурилсульфата для стирки шерстяных, шелковых и синтетических тканей

Паста на основе Эстонола-2 для стирки шерстяных, шелковых и синтетических тканей

Паста на основе триэтаноламиновой соли вторичных алкилсульфоэфиров для стирки шерстяных, шелковых и синтетических тканей

Паста, выпускаемая отечественной промышленностью для стирки шерстяных, шелковых и синтетических тканей

Жидкое моющее средство, выпускаемое отечественной промышленностью, для стирки шерстяных, шелковых и синтетнческих тканей

Жидкое моющее средство на основе Эстонола-2 для стирки шерстяных, шелковых и синтетических тканей

\section{0}

\section{3}

71,5

60,7

112

\section{0}

93,3

93,7

52,7

\section{0}

92,6

98,5

128

102

112

155 
триэтаноламиновой соли первичного лаурилсульфата как в чистом виде, так и в составе композиций моющих средств.

Сравнительно невысокая моющая способность чистого активного вещества объясняется тем, что в препаратах, содержащих меньше активного вещества, присутствуют триэтаноламиновые соли сульфатов, которые обладают некоторой дополнительной моющей способностью. Это подтверждается тем, что паста для стирки шерстяных, шелковых и синтетических тканей на его основе по моющей способности не уступает такой же пасте на основе триэтаноламиновой соли первичного лаурилсульфата. Испытания моющей способности показали, что Эстонол-2 может быть успешно использован в композициях моющих средств, применяемых для стирки шерстяных, шелковых и синтетических тканей.

\title{
Выводы
}

1. Показана возможность получения триэтаноламиновых солей вторичных алкилсульфоэфиров по технологии, используемой для синтезирования натриевых солей. Количество изопропилового спирта при этом может быть уменьшено вдвое, в результате чего увеличивается выход полезных продуктов в 1,2-1,3 раза.

2. Данные о поверхностном натяжении и критической концентрации мицеллообразования свидетельствуют о том, что триэтаноламиновые соли вторичных алкилісульфоэфиров являются полноценными ПАВ.

3. Высокая пенообразующая способность Эстонола-2 позволяет рекомендовать его для применения в композициях шампуней и пеномоющих средств.

4. Моющая способность Эстонола-2 составляет $60-70 \%$ по сравнению с моющей способностью лаурилсульфата натрия. Әстонол-2 может быть использован в композициях жидких и пастообразных моющих средств.

\section{ЛИТЕРАТ У РА}

1. Новые товары бытовой химии. М., 1971, с. 12-13.

2. Каталог фирмы «Dow Chemical». 1970, clns. 76/4.

3. Soap a Chem. Spec., 47, 113 (1971).

4. Новые товары бытовой химии. М., 1971, с. 32.

5. Seffen, Ole-Fette-Wachse, 95, S. 543-544 (1969).

6. Seffen, Ole-Fette-Wachse, 95, S. 589-592 (1969).

7. Новые товары бытовой химин. М., 1971, с. 41.

8. Руководство по методам исследования, технологическому контролю и учету производства в масложировой промышленности. Л., IV, 1963.

\author{
Институт химии \\ Академии наук Эстонской ССР
}

Поступила в редакцию 20/VIII 1975 


\section{S. FAINGOLD, Tatjana LESMENT, \\ N. MASPANOV, E. GORDEJEVA}

\section{SEKUNDAARSETE ALKUOLLULFAATIDE TRIETANOOLAMIINI SOOLADE SAAMINE JA NENDE PINDAKTIIVSED OMADUSED}

Esitatakse sekundaarsete alküülsulfaatide trietanoolamiini soolade saamise meetod ja nende pindaktiivsed omadused. Katsetest ilmneb, et tegemist on täisväärtuslike pindaktiivsete ainetega, mida on soovitatav kasutada šampoonides, vaht- ja vedelates pesemisvahendites.

S. FAINGOLD, Tatiana LESMENT,

N. MASPANOV, E. GORDEYEVA

THE METHOD OF OBTAINING TRIETHANOLAMINE SECONDARY ALKYL SULPHATES AND THEIR SURFACE ACTIVE PROPERTIES

The method of obtaining triethanolamine secondary alkyl sulphates and the determination of their surface properties are described.

It has been found that triethanolamine secondary alkyl sulphates are good surfactants and they may be recommended for the composition of shampoos and liquid detergents. 